\title{
Writing Tips for Your Next Research Article
}

Matteo Cavalleri ${ }^{1}$

${ }^{1}$ Affiliation not available

February 18, 2021

\begin{abstract}
An academic article is often regarded just as an archival device for storing a completed research program. Actually, a successful paper is also the blueprint for planning your research in progress. We will discuss how to write articles that not only successfully navigate the peer-review process, but are also discovered, read, cited, and make an impact in the research community.
\end{abstract}

Rich media available at https://speakerdeck.com/teowaits/writing-tips-for-your-next-researcharticle

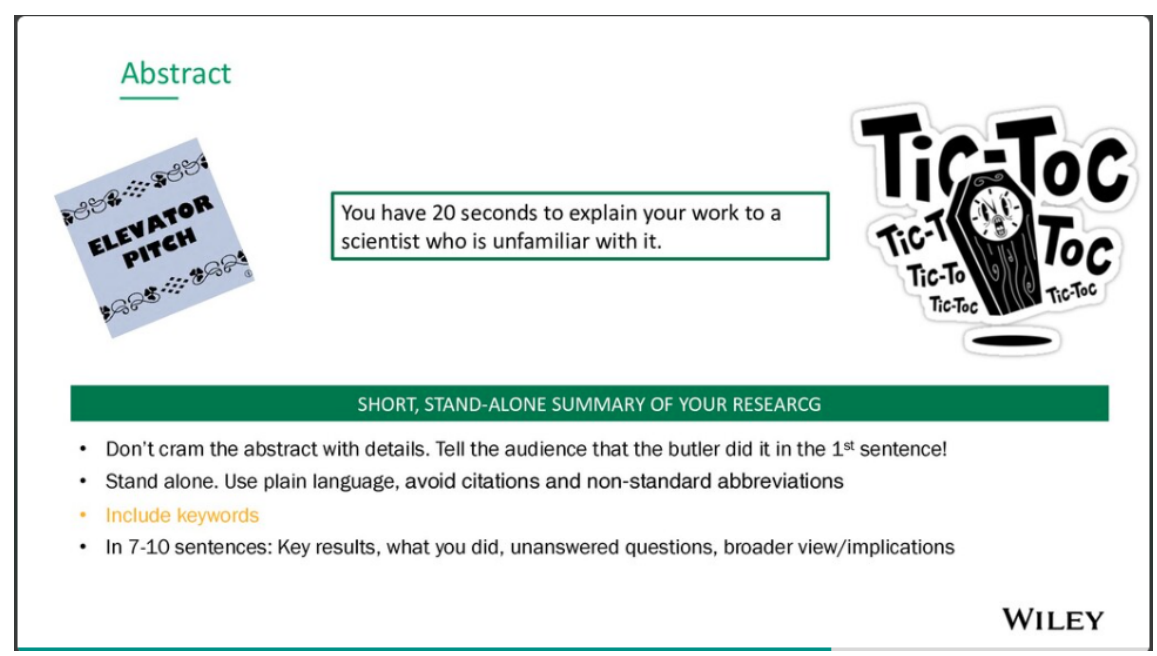

Figure 1: The ABSTRACT: Tell the audience the butler did it! 